\title{
Aqueous phototransformation of bisphenol S: the competitive radical-attack pathway to p-hydroxybenzenesulfonic acid
}

\author{
Xiaowen Wang, Jiahai Ma, Zhenpeng Wang, Rongrong Guo \\ and Xuefeng Hu
}

\begin{abstract}
The kinetics, environmental influencing factors, products and reaction mechanism of aqueous phototransformation of bisphenol S (BPS), as an alternative to bisphenol A, which is of environmental concern, were investigated. $p$-Hydroxybenzenesulfonic acid, as the major transformation product was confirmed by gas chromatography - mass spectrometry, electrospray ionization, ${ }^{1} \mathrm{H}$ nuclear magnetic resonance and fluorescence spectrum analysis. A reaction pathway was proposed based on the reactive oxygen species related results by electron paramagnetic resonance and radical traps. The competition of the excited state of BPS between transferring electron to $\mathrm{O}_{2}$ to $\bullet \mathrm{O}_{2}^{-}$and directly oxidizing $\mathrm{H}_{2} \mathrm{O}$ to $\bullet \mathrm{OH}$ was revealed.

Key words | bisphenol S, p-hydroxybenzenesulfonic acid, phototransformation, reactive oxygen species

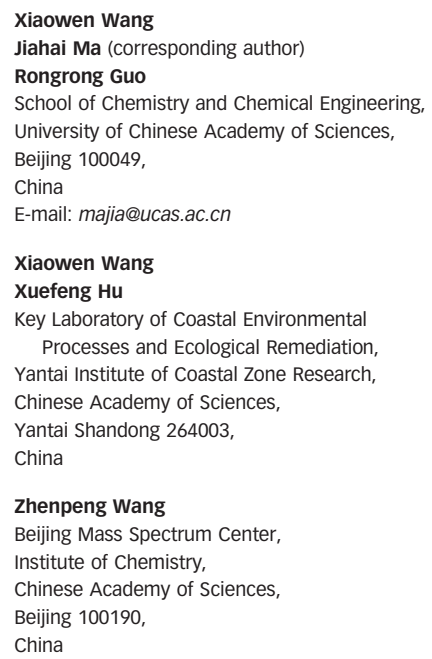

\section{INTRODUCTION}

Endocrine-disrupting chemicals, threatening natural water environments, have been studied widely spread over the past decades. Bisphenol A (BPA, 2,2-bis-(4-hydroxy-phenyl) propane or $4,4^{\prime}$-isopropylidenediphenol, Figure 1 ), is an important industrial chemical used for the production of epoxy resins and polycarbonate plastics, which are used in various food and drink packaging applications, baby bottles and dental sealants (Staples et al. I998). As a representative endocrine disrupter, BPA causes not only a strong estrogenic endocrine-disrupting effect (Alexander et al. I988), but also various diseases including cancer (Suarez et al. 2000). Concerns about the health risk of BPA are increasing, and restrictions/regulations have been put forward to limit BPA's application in consumer products, and some countries like Japan have banned BPA application completely.

BPA is being replaced with a number of alternatives, such as bisphenol S (BPS; 4,4'-sulphonyldiphenol), bisphenol B (2,2'-bis(4-hydroxyphenyl)butane) and bisphenol $\mathrm{F}$ (4,4'dihydroxydiphenyl-methane) in industrial chemicals and daily-life customer goods. A variety of treatment techniques for BPA in water have been examined using physical, biological, electrochemical and photochemical procedures. Nishiki and colleagues used $\beta$-cyclodextrin-linked chitosan beads to remove BPA (Nishiki et al. 200o). Lobos et al. (I992) isolated a gram-negative aerobic bacterium (strain MV1) that utilized BPA as the sole carbon source. Some researchers (Ohko et al. 200I; Fukahori et al. 2003) have reported the photocatalytic degradation of $\mathrm{BPA}$ in $\mathrm{TiO}_{2}$ aqueous suspension, and various intermediate products such as phenol, $p$-hydroquinone, $p$-isopropenylphenol, $p$-hydroxybenzaldehyde, and 4-hydroxyphenyl-2-propanol were found. Due to the very similar molecular structure of bisphenol $\mathrm{B}$, bisphenol $\mathrm{F}$ and BPA, it is reasonable that their phototransformation behavior is similar, too.

As BPS is regarded as the alternative of BPA, the demand and production of BPS in China and Japan are increasing continuously (Liu 2005). Because of its increasingly widespread application, the potential water contamination of and human exposure to BPS is very high. Further, BPS has a 


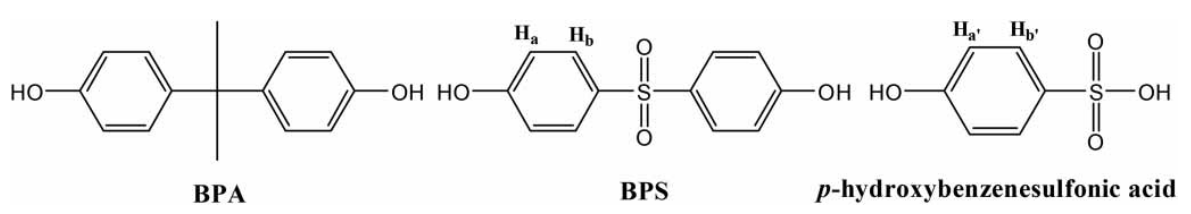

Figure 1 | Molecular structure of BPA, BPS and p-hydroxybenzenesulfonic acid.

different molecular structure to other bisphenol analogs, and thus the study of the environmental fate of BPS is urgently needed. The environmental and human body concentration of BPS has been measured in paper products and currency bills, sediments and urine (Liao et al. 2012a, b, c). However, studies on the environmental phototransformation of BPS are limited. The elementary degradation kinetics of BPS under UV $(\lambda=254 \mathrm{~nm})$ was studied by Cao et al. (20I0, 20I2); however, the products of phototransformation and detailed reaction pathway under the full solar spectrum remain unclear until now.

The objective of the present work is to study: (i) whether BPS could be easily transformed under photo-irradiation and, if so, whether the major transformation product is unharmful or not; and (ii) whether reactive oxygen species (ROS) are responsible for the transformation and, if so, which reactive species plays the dominating role. Thus, the present study focused on the phototransformation product and detailed reaction pathway of BPS. Better understanding of these reactions is needed for both the elucidation of the environmental fate of BPS and the successful application of suitable remediation technologies for BPS.

\section{EXPERIMENTAL}

\section{Materials and chemicals}

BPS, BPA, Aldrich humic acid, furfuryl alcohol and Rose Bengal were obtained from Alfa Aesar. p-Hydroxybenzenesulfonic acid was purchased from $\mathrm{J} \& \mathrm{~K}$ Scientific Technology Co., Ltd. The spin trap reagent, 5,5-dimethyl-1pyrroline- $N$-oxide (DMPO), was from Sigma. Benzoquinone and $\mathrm{FeCl}_{3}$ were of analytical grade. Deionized water was distilled and purified further in a Milli-Q system to a resistivity greater than $18 \mathrm{M} \Omega$-cm.

BPS dissolved much more easily in water with a tiny amount of ethanol than in pure water, and the corresponding absorption spectra had little difference (Figure S1, available online at http://www.iwaponline.com/wst/070/ 257.pdf), thus the former was used in the whole work except where noted. A $4.0 \times 10^{-4} \mathrm{~mol} / \mathrm{L}$ stock solution of
BPS was prepared by dissolving $25.0 \mathrm{mg}$ BPS in $245 \mathrm{~mL}$ water with $5 \mathrm{~mL}$ ethanol and was kept at $4{ }^{\circ} \mathrm{C}$; the test solution of different reagents was prepared by spiking water with an appropriate amount of the stock solution to obtain a final concentration of $4.0 \times 10^{-5} \mathrm{~mol} / \mathrm{L}$, and the ethanol content was $<0.2 \%$.

\section{Photochemical experiments}

Photochemical experiments were conducted in a photochemical reaction chamber using a $350-\mathrm{W}$ xenon lamp (Shanghai Irradiation Lamp Co., Ltd, China) as the irradiation source, and Figure S2 (available online at http://www.iwaponline.com/wst/070/257.pdf) shows the emission spectrum. The reaction solution volume was $50 \mathrm{~mL}$, and the temperature was maintained at $25 \pm 1^{\circ} \mathrm{C}$. At given reaction time intervals, approximate $3 \mathrm{~mL}$ samples were taken out and analyzed immediately. Each experiment was conducted at least twice with relative errors less than $5 \%$. All experiments were carried out under aerated condition, except that the specially noted $\mathrm{O}_{2}$-free experiments were done under ultrapure $\mathrm{N}_{2}$.

\section{Instrument analysis}

The absorption spectra of the BPS solution were recorded on a UV-2550 UV-visible spectrophotometer (Shimadzu, Japan), and the reaction kinetics for BPS transformation was determined by measuring its absorbance change at $258 \mathrm{~nm}$ with time.

Fluorescence spectra were measured in a quartz cuvette using a HORIBA FluoroMax-4 spectrofluorometer.

${ }^{1} \mathrm{H}$ NMR (nuclear magnetic resonance) spectra were acquired using a $600 \mathrm{MHz}$ Agilent DD2 spectrometer: collected for 16 repetitions, relax delay $5.000 \mathrm{~s}$, pulse width 45.0 degrees, acquire time $1.704 \mathrm{~s}$ and width 9,615.4 Hz.

Electrospray ionization (ESI) mass spectra were obtained in negative-ion ionization mode on a mass spectrometer (micrQTOF Bruker, Germany), using a double ion funnel electrospray ion source. The mass spectrum acquisition rate was 20 per second. 
Gas chromatography-mass spectrometry (GC-MS) experiments were performed on a GCMS-QP2010 (Shimadzu, Japan). A DB-5 fused-silica capillary column ( $30 \mathrm{~m} \times 0.25 \mathrm{~mm}$ i.d., $0.25 \mu \mathrm{m}$ thickness) was used for GC separation, and helium was used as the carrier gas at $1 \mathrm{~mL} / \mathrm{min}$. The oven temperature was initially $100^{\circ} \mathrm{C}$ for $2 \mathrm{~min}$, increased to $300{ }^{\circ} \mathrm{C}$ at $20^{\circ} \mathrm{C} / \mathrm{min}$, and held at $300{ }^{\circ} \mathrm{C}$ for $20 \mathrm{~min}$. The injector and source temperatures were set at 250 and $200{ }^{\circ} \mathrm{C}$, respectively.

EPR (electron paramagnetic resonance) experiments were performed on a JES FA200 spectrometer (JEOL, Japan): microwave power $4.0 \mathrm{~mW}$, time constant $0.03 \mathrm{~s}$, sweep time $2.0 \mathrm{~min}, 1$ accumulation and 4,096 data points. The amount of DMPO added was $4 \times 10^{-3} \mathrm{~mol} / \mathrm{L}$. Samples were placed in a quartz capillary tube, and the same tube was used for all the measurements to minimize errors.

\section{RESULTS AND DISCUSSION}

\section{Phototransformation of BPS}

The initial absorption spectrum (before irradiation) of BPS had two peaks at 234 and $258 \mathrm{~nm}$, and the second peak was the determination wavelength for its higher molar absorptivity. The initial peaks of BPS decreased as irradiation time increased, indicating that the concentration of BPS decreased as phototransformation proceeded (Figure 2(a)). Figure 2(b) shows the transformation of BPS under $\mathrm{N}_{2}$ condition and air condition, respectively, suggesting that dissolved oxygen did play a role in the phototransformation process (see discussions below). Besides, Figure 2(c) shows that the phototransformation efficiency of BPS was higher than that of BPA, which indicated that BPS had shorter lifetime than BPA in aqueous environment.

\section{Product analysis}

The phototransformation products of BPS were first examined by ESI-MS and GC-MS (Figure 3, Table 1, Figure S3, available online at http://www.iwaponline.com/wst/070/ 257.pdf); one main product was identified by the molecular ion and mass fragment peaks and by comparison with GCMS library data. As shown in Figure 3, the ion peak intensity of $\mathrm{m} / \mathrm{z} 249$ decreased, while the ion peak intensity of $\mathrm{m} / \mathrm{z}$ 172.3 increased with irradiation. Herein, the ion at $\mathrm{m} / \mathrm{z}$ 249 was identified as the deprotonated molecule $\left[(\mathrm{M}-\mathrm{H})^{-}\right]$ of BPS, and another ion at $\mathrm{m} / \mathrm{z} 172.3$ was identified as the deprotonated molecule $\left[(\mathrm{M}-\mathrm{H})^{-}\right]$of the phototransformation
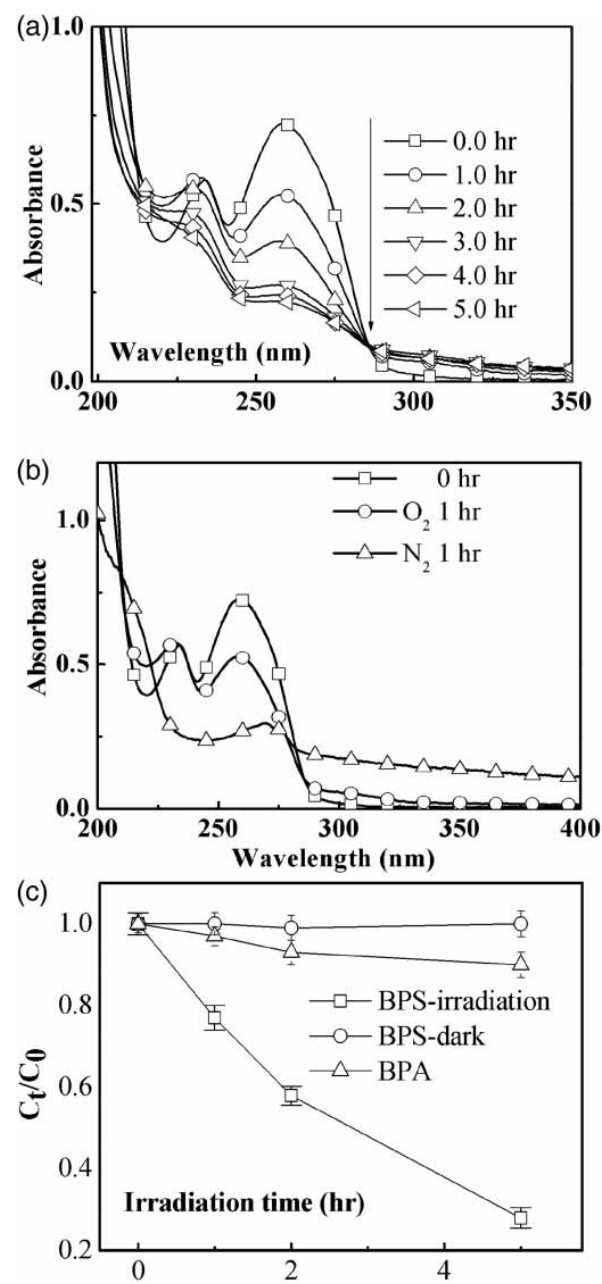

Figure 2 Absorption spectra of the BPS $\left(4.0 \times 10^{-5} \mathrm{~mol} / \mathrm{L}\right)$ solution at (a) different irradiation time of $0-5 \mathrm{hr}$ and (b) different aerated conditions of $\mathrm{O}_{2}$ or $\mathrm{N}_{2}$. (c) Comparison of degradation rate between BPA and BPS in dark or under irradiation.

product of BPS. Further, GC-MS results (Table 1 and Figure S3) identified the product at the retention time $2.824 \mathrm{~min}$ as corresponding to $p$-hydroxybenzenesulfonic acid; and it was exactly consistent with ESI-MS peak at $\mathrm{m} / \mathrm{z}$ 173. More important, the mass spectra results suggested that there were no other phototransformation intermediates besides $p$-hydroxybenzenesulfonic acid.

In order to further confirm whether the major product was $p$-hydroxybenzenesulfonic acid, phototransformation samples were compared with the standard sample by ${ }^{1} \mathrm{H}$ NMR and fluorescence spectra. The temporal ${ }^{1} \mathrm{H}$ NMR spectral patterns in the phototransformation of BPS in $\mathrm{CD}_{3} \mathrm{OD}$ solution are shown in Figure 4(a). The doublet peak of the 3- and 5-position protons $\left(\mathrm{H}_{\mathrm{b}}\right)$ of BPS appeared at $7.72,7.74 \mathrm{ppm}$, and the doublet peak of the 2- and 6position protons $\left(\mathrm{H}_{\mathrm{a}}\right)$ appeared at $6.88,6.90 \mathrm{ppm}$. The 
(a)

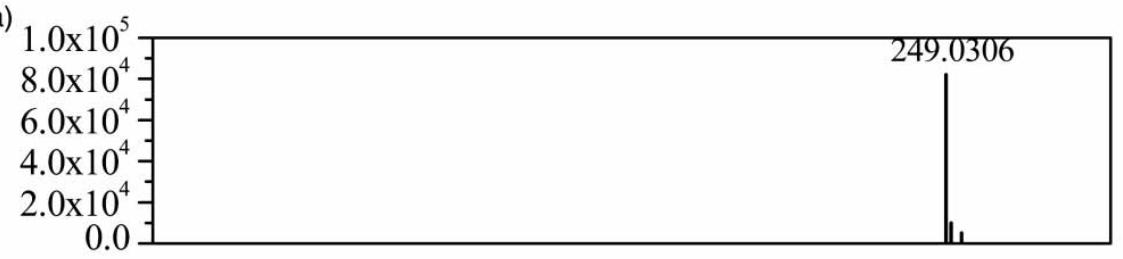

(b) $1.0 \times 10^{5}$

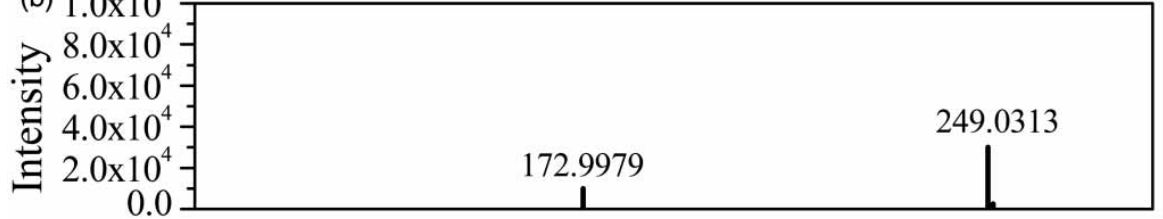

(c)

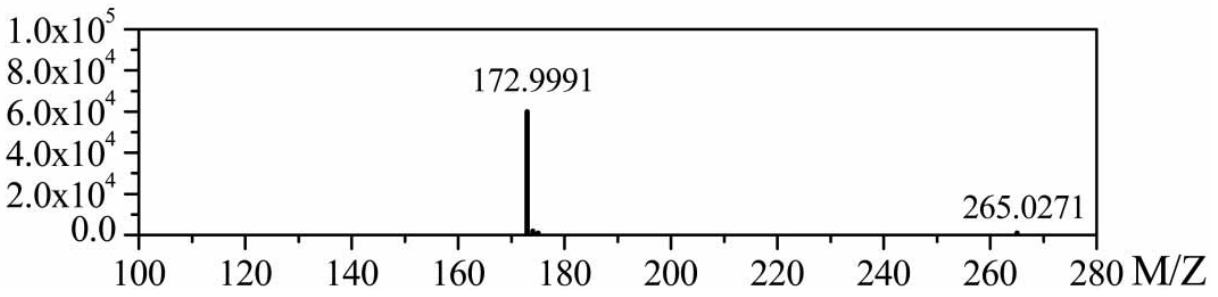

Figure 3 | ESI-MS for BPS phototransformation after certain irradiation time: (a) $0 \mathrm{hr}$, (b) $1 \mathrm{hr}$ and (c) $3 \mathrm{hr}$.

Table 1 | GC-MS information about phototransformation products of BPS

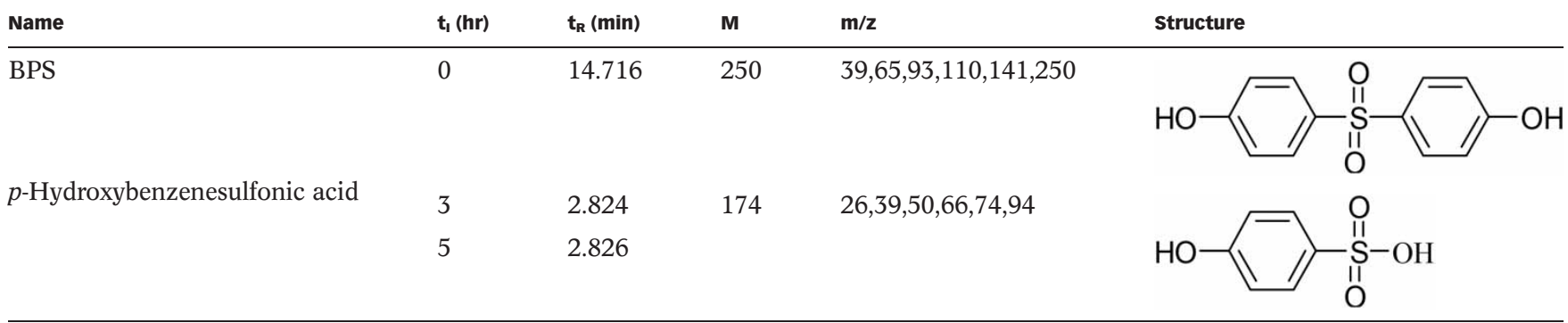

$t_{1}$ - irradiation time. $t_{R}$ - retention time. $\mathrm{M}$ - molecular weight.

ratio of each signal peak area, against TMS (trimethylsilylated derivatization) reference, was 1 (6.88, $6.90 \mathrm{ppm}): 1$ (7.72, 7.74 ppm). Finally, both peaks disappeared after 1.5 hr of irradiation. Simultaneously, two new doublet peaks $(6.78,6.80$ and $7.66,7.68 \mathrm{ppm})$ attributed to $p$-hydroxybenzenesulfonic acid (i.e. $\mathrm{H}_{\mathrm{a}}$, and $\mathrm{H}_{\mathrm{b}}$ ) appeared. The quantitative transformation of BPS and generation of products are shown in Figure 4(b). p-Hydroxybenzenesulfonic acid was the only product which could be observed in the ${ }^{1} \mathrm{H}$ NMR, and its generating ratio was $41 \%$ after $1.5 \mathrm{hr}$ of irradiation, while BPS signals completely disappeared at that time. The non-balance of element S from NMR results suggested that one or more products, which could not be observed by ${ }^{1} \mathrm{H}$ NMR, were produced, and the products probably were not organic sulfur species any more, and could be volatile $\mathrm{SO}_{2}$ and $\mathrm{SO}_{3}$. Also, Figure 4(c) shows that the relative fluorescence intensity increased as irradiation time increased, and the emission peak kept at around $470 \mathrm{~nm}$, which meant new product(s) had been produced during the phototransformation; the inset in Figure 4(c) is the fluorescence of $p$-hydroxybenzenesulfonic acid with emission maximum at $463 \mathrm{~nm}$, and it confirmed that $p$-hydroxybenzenesulfonic acid was probably the major phototransformation product again.

\section{Phototransformation mechanism}

Dissolved oxygen in water could participate in BPS phototransformation by producing oxidative ROS such as ${ }^{1} \mathrm{O}_{2}$ (Chen et al. 2008) and $\cdot \mathrm{O}_{2}^{-}$(Draper \& Crosby 1983), which 
(a)

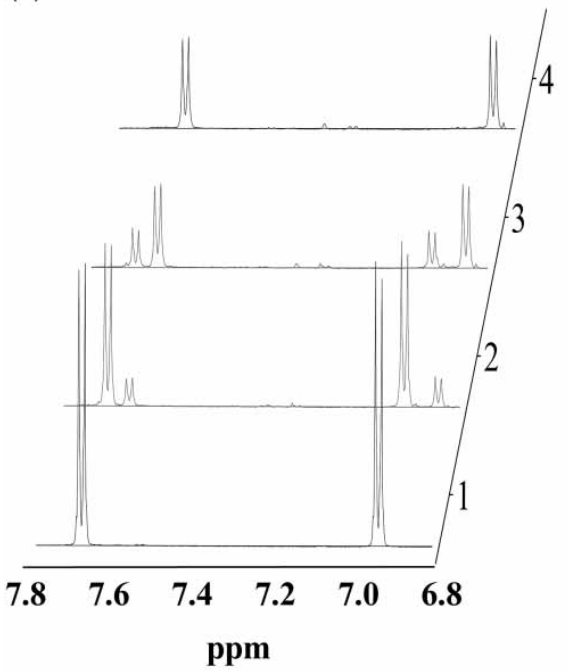

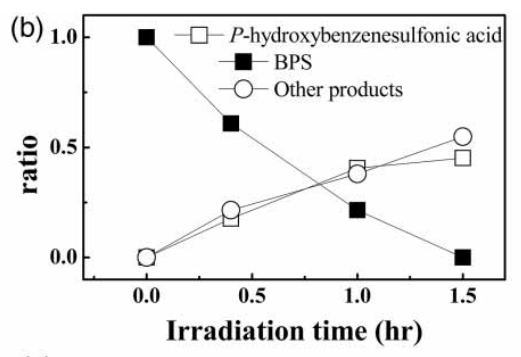

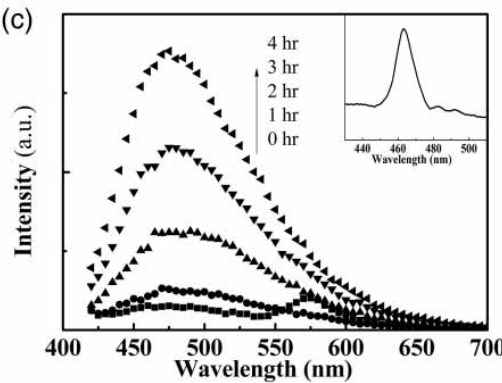

Figure 4 | The ${ }^{1} \mathrm{H}$ NMR (a) and corresponding quantitative analysis (b) and fluorescence spectra (c) of the BPS (4.0 $\times 10^{-5}$ mol/L) solution under irradiation. For (a) at different irradiation time, 1: $0 \mathrm{hr} ; 2: 0.4 \mathrm{hr} ; 3: 1 \mathrm{hr} ; 4: 1.5 \mathrm{hr}$. The inset in (c) is the fluorescence spectrum of $p$-hydroxybenzenesulfonic acid $\left(4.0 \times 10^{-4} \mathrm{~mol} / \mathrm{L}\right)$.

may greatly affect the degradation of BPS. As shown in Figure 2(b), the transformation of BPS differed markedly between $\mathrm{N}_{2}$ condition and air condition, confirming that dissolved oxygen did contribute to the phototransformation process (see discussion below).

Further, the phototransformation of BPS in the presence of several radical initiators or traps such as humic acid (HA), Fe(III), Rose Bengal, methanol, furyl alcohol and p-benzoquinone was examined, as shown in Table 2.

HA molecules absorb light and generate excited triplet $\left({ }^{3} \mathrm{HA}^{*}\right)$, and ROS could be generated from the reaction between ${ }^{3} \mathrm{HA}^{*}$ and oxygen (Richard et al. 1997; Zepp et al. I985; Zhan et al. 2005), and could attack BPS efficiently. From Table 2, the effects of HA on accelerating the phototransformation of BPS, suggested the important role of ROS.

\begin{tabular}{|c|c|c|}
\hline Target & Additive $\left(10^{-3} \mathrm{~mol} / \mathrm{L}\right)$ & Degradation $\% t=a, b$ \\
\hline Control & None & $23^{\mathrm{a}} 72^{\mathrm{b}}$ \\
\hline Generate ROS & $\mathrm{HA} / 2$ (mg/L) & $80^{\mathrm{b}}$ \\
\hline Generate $\cdot \mathrm{OH}$ & $\mathrm{Fe}(\mathrm{III}) / 1$ & $91^{\mathrm{b}}$ \\
\hline Generate ${ }^{1} \mathrm{O}_{2}$ & Rose Bengal/0.4 & $32^{\mathrm{a}}$ \\
\hline Trap $\cdot \mathrm{OH}$ & Methanol/1 & $6^{\mathrm{a}}$ \\
\hline Trap ${ }^{1} \mathrm{O}_{2}($ main $)+\cdot \cdot \mathrm{OH}$ & Furfuryl alcohol/1 & $10^{\mathrm{a}}$ \\
\hline Trap $\mathrm{O}_{2}^{--}$ & $\begin{array}{l}\text { Benzoquinone/0.1 } \\
\text { Benzoquinone/100 }\end{array}$ & $\begin{array}{l}46^{\mathrm{a}} \\
61^{\mathrm{a}}\end{array}$ \\
\hline
\end{tabular}

alrradiation $1 \mathrm{hr}$.

birradiation 5 hr.
Addition of $\mathrm{Fe}$ (III) also accelerated the transformation of BPS. It is well known that UV light could directly lead to $\cdot \mathrm{OH}$ formation and regeneration of $\mathrm{Fe}^{2+}$ from the photolysis of the $\mathrm{Fe}(\mathrm{OH})^{2+}$ in solution as follows (Ma et al. 2005):

$\mathrm{Fe}(\mathrm{OH})^{2+}+h v \rightarrow \mathrm{Fe}(\mathrm{II})+\cdot \mathrm{OH}$

The $\cdot \mathrm{OH}$ quantum yield for Equation (1) is 0.14 at $313 \mathrm{~nm}$ and 0.017 at $360 \mathrm{~nm}$ (Zuo \& Hoigne 1992). The - $\mathrm{OH}$ radical has a high oxidizing potential for the degradation of organic pollutants in water, and thus it suggested that the $\cdot \mathrm{OH}$ plays an important role in oxidation and promotes the phototransformation of BPS.

Further, compared with control reaction, the degradation of BPS was not remarkably accelerated in the presence of Rose Bengal, which was used for efficiently generating ${ }^{1} \mathrm{O}_{2}$, and thus it suggested that ${ }^{1} \mathrm{O}_{2}$ did not contribute much to the phototransformation of BPS.

Simultaneously, excess amounts of methanol, $p$-benzoquinone and furyl alcohol were added as effective scavengers for $\cdot \mathrm{OH}, \cdot \mathrm{O}_{2}^{-}$and ${ }^{1} \mathrm{O}_{2}$ (Sun \& Pignatello 1992; Li et al. 2012), respectively. Table 2 shows that BPS degradation rates were suppressed in the presence of excess methanol and furyl alcohol, which confirmed that $\cdot \mathrm{OH}$ could greatly affect BPS phototransformation; also, the small deviation between the two scavengers also confirmed that ${ }^{1} \mathrm{O}_{2}$ really contributed slightly in the process. $p$-Benzoquinone was used as $\cdot \mathrm{O}_{2}^{-}$trap and it was found that the 


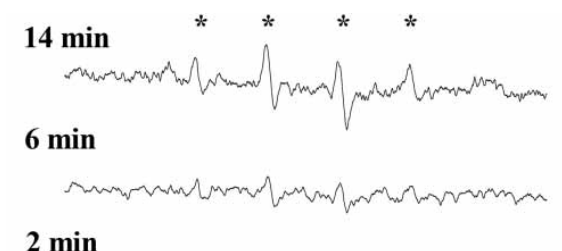

$2 \min$

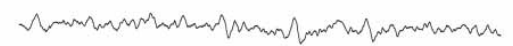

0 min

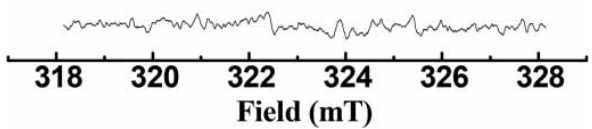

Figure 5 | EPR spectra of the DMPO-HO• adducts in the irradiated BPS solution.

phototransformation process was significantly accelerated for both concentrations $\left(10^{-4}\right.$ and $\left.10^{-1} \mathrm{M}\right)$. More important, when the amount of benzoquinone was increased dramatically, the BPS degradation efficiency had no corresponding increase, and thus it confirmed that the observed increased rate of BPS degradation was indeed due to trapping of $\cdot \mathrm{O}_{2}^{-}$ and not due to the benzoquinone-sensitized reaction (Ma et al. 2006). There was a readily possible explanation for this: first, $\cdot \mathrm{BPS}^{+}$would be accumulated because $\cdot \mathrm{O}_{2}^{-}$ was trapped (reaction (2)); second, $\cdot \mathrm{BPS}^{+}$was more easily degraded than BPS under $\cdot \mathrm{OH}$ attack. More important, the clearly accelerated phototransformation process with $\cdot \mathrm{O}_{2}^{-}$ trap not only proved that $\cdot \mathrm{O}_{2}^{-}$played a role but also suggested that there may be a competition between $\cdot \mathrm{O}_{2}^{-}$and $\cdot \mathrm{OH}$ in the phototransformation process.

Photoexcitation of anthraquinone and its single- or double-substituted sulfonate derivatives leads to efficient production of a semiquinone radical and $\cdot \mathrm{OH}$ by apparent one-photon photooxidation of water (Ononye et al. I986; Ma et al. 20II). Here, it was suggested that BPS could perform the same reaction as the quinones do. Therefore, on the basis of the above experiment data, we propose the two competitive reaction pathways as follows:

BPS $^{*}+\mathrm{O}_{2} \rightarrow \cdot \mathrm{BPS}^{+}+\cdot \mathrm{O}_{2}^{-}$

$\mathrm{BPS}^{*}+\mathrm{H}_{2} \mathrm{O} \rightarrow(\mathrm{BPS}-\mathrm{H})^{\bullet}+\cdot \cdot \mathrm{OH}$

BPS absorbed light, then generated BPS* would react with $\mathrm{O}_{2}$ and $\mathrm{H}_{2} \mathrm{O}$ in the solution, producing $\cdot \mathrm{O}_{2}^{-}$and $\cdot \mathrm{OH}$. The phototransformation of BPS involves competitive attacking of substrate by $\cdot \mathrm{O}_{2}^{-}$due to electron transfer from the excited state of BPS (BPS*) to dissolved $\mathrm{O}_{2}$ and by - $\mathrm{OH}$ from BPS* directly oxidizing $\mathrm{H}_{2} \mathrm{O}$, and the latter contributed more than the former. Indeed, the EPR spin-trap results evidenced the signals of DMPO-HO in the irradiated BPS solution. As illustrated in Figure 5, four characteristic peaks of DMPO-HO were obviously observed after irradiation, and the signal intensity increased with irradiation time; however, no such signals were detected in the dark. Direct addition of hydrogen peroxide had no acceleration effect on the phototransformation of BPS; thus it excluded that the observed DMPO-HO- signals came from other pathways, such as the photolysis of hydrogen peroxide which might be formed from superoxide radicals. The fact that $\cdot \mathrm{OH}$ was produced provided solid evidence that photo-excited BPS could oxidize $\mathrm{H}_{2} \mathrm{O}$ to produce -OH. Further, the $\mathrm{O}_{2}$-free results also supported this mechanism, i.e. in the absence of ${ }^{1} \mathrm{O}_{2}$ and $\cdot \mathrm{O}_{2}^{-}$, the phototransformation of BPS proceeded much faster, strongly suggesting the reaction pathway of BPS's direct oxidization of $\mathrm{H}_{2} \mathrm{O}$ to produce $\cdot \mathrm{OH}$.

Therefore, on the basis of the above experiment data, the pathway of phototransformation of BPS could be

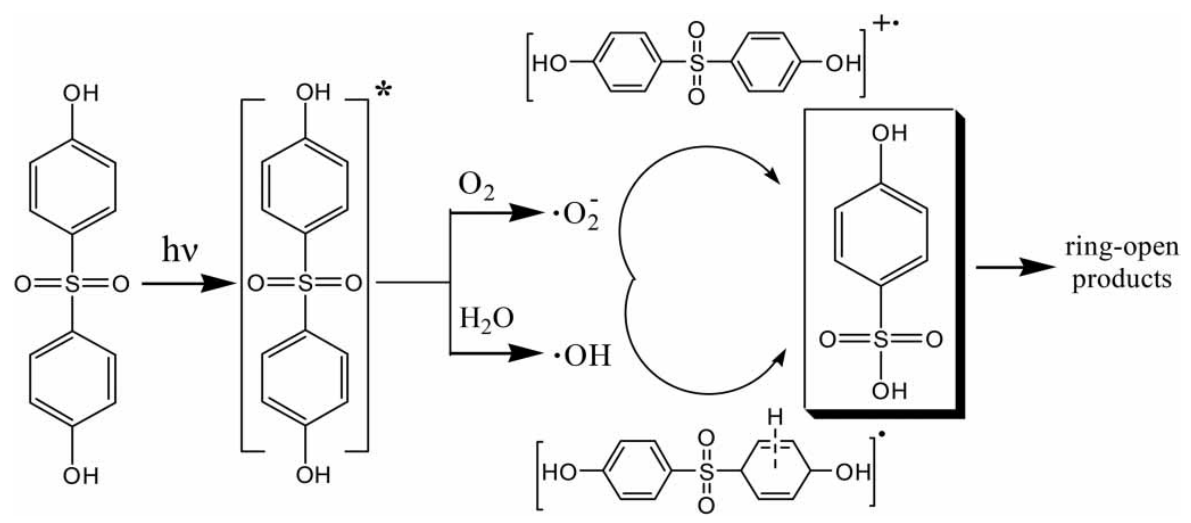

Figure 6 | The proposed phototransformation pathway of BPS. 
illustrated in Figure 6. Under the aerated condition, the BPS phototransformation mechanism involved competitive attacking of substrate by $\cdot \mathrm{O}_{2}^{-}$, due to electron transfer from BPS* to $\mathrm{O}_{2}$, and $\cdot \mathrm{OH}$ from BPS* directly oxidizing $\mathrm{H}_{2} \mathrm{O}$, leading to $p$-hydroxybenzenesulfonic acid; since $\cdot \mathrm{OH}$ has much stronger oxidizing potential than $\cdot \mathrm{O}_{2}^{-}(\mathrm{Ma}$ et $a l$. 2006), $\cdot \mathrm{OH}$ should contribute more than $\cdot \mathrm{O}_{2}^{-}$in the phototransformation. And under $\mathrm{O}_{2}$-free condition, due to the lack of competition from the $\cdot \mathrm{O}_{2}^{-}$route, $\cdot \mathrm{OH}$ as the only radical played the dominating role, and thus the phototransformation became much more efficient.

\section{CONCLUSION}

Based on the above results and discussions, in contrast to BPA, the aqueous phototransformation of BPS could readily proceed. Various radical traps and further EPR results confirmed $\cdot \mathrm{OH}$ and $\cdot \mathrm{O}_{2}^{-}$competitively playing a role in the phototransformation of BPS under aerated condition, and the main product was unharmful $p$-hydroxybenzenesulfonic acid identified by ESI-MS, NMR and fluorescence. Under $\mathrm{O}_{2}$-free condition, $\cdot \mathrm{OH}$ was exclusively formed and played the dominating role, and thus the phototransformation became much more efficient. Better understanding of these reactions is very important not only for studying the environmental fate of BPS but also for the successful treatment of practical wastewaters containing BPS component.

\section{ACKNOWLEDGEMENTS}

This work was supported by the NSFC (Nos 21007089, 21377126 and 41076040) and the SRF for ROCS, SEM of China.

\section{REFERENCES}

Alexander, H. C., Dill, D., Smith, L., Guiney, P. \& Dorn, P. 1988 Bisphenol A: acute aquatic toxicity. Environmental Toxicology and Chemistry 7 (1), 19-26.

Cao, G. P., Wang, B., Ding, Q. \& Zong, L. 2oro Determination of bisphenol S by ultraviolet spectrophotometric method. Chemistry \& Bioengineering 27 (10), 80-88.

Cao, G. P., Lu, J. \& Wang, G. 20I2 Photolysis kinetics and influencing factors of bisphenol $\mathrm{S}$ in aqueous solutions. Journal of Environmental Sciences 24 (5), 846-851.

Chen, Y., Hu, C., Qu, J. \& Yang, M. 2008 Photodegradation of tetracycline and formation of reactive oxygen species in aqueous tetracycline solution under simulated sunlight irradiation. Journal of Photochemistry and Photobiology A: Chemistry 197 (1), 81-87.

Draper, W. M. \& Crosby, D. 1983 Photochemical generation of superoxide radical anion in water. Journal of Agricultural and Food Chemistry 31 (4), 734-737.

Fukahori, S., Ichiura, H., Kitaoka, T. \& Tanaka, H. 2003 Capturing of bisphenol A photodecomposition intermediates by composite $\mathrm{TiO}_{2}$-zeolite sheets. Applied Catalysis $\mathrm{B}$ : Environmental 46 (3), 453-462.

Li, Y., Wen, B., Yu, C., Chen, C., Ji, H., Ma, W. \& Zhao, J. 2012 Pathway of oxygen incorporation from $\mathrm{O}_{2}$ in $\mathrm{TiO}_{2}$ photocatalytic hydroxylation of aromatics: oxygen isotope labeling studies. Chemistry - A European Journal 18 (7), 2030-2039.

Liao, C. Y., Liu, F., Alomirah, H., Loi, V., Mohd, M., Moon, H., Nakata, H. \& Kannan, K. 2orza Bisphenol S in urine from the United States and seven Asian countries: occurrence and human exposures. Environmental Science \& Technology 46 (12), 6860-6866.

Liao, C. Y., Liu, F. \& Kannan, K. 20ı2b Bisphenol S, a new bisphenol analogue, in paper products and currency bills and its association with bisphenol A residues. Environmental Science \& Technology 46 (12), 6515-6522.

Liao, C. Y., Liu, F., Moon, H., Yamashita, N., Yun, S. \& Kannan, K. 20I2c Bisphenol analogues in sediments from industrialized areas in the United States, Japan, and Korea: spatial and temporal distributions. Environmental Science \& Technology 46 (21), 11558-11565.

Liu, Y. 2005 Bisphenol, S. Fine and Specialty Chemicals 13 (4), 13-14.

Lobos, J. H., Leib, T. \& Su, T. 1992 Biodegradation of bisphenol A and other bisphenols by a Gram-negative aerobic bacterium. Applied and Environmental Microbiology 58 (6), 1823-1831.

Ma, J. H., Song, W., Chen, C., Ma, W., Zhao, J. \& Tang, Y. 2005 Fenton degradation of organic compounds promoted by dyes under visible irradiation. Environmental Science \& Technology 39 (15), 5810-5815.

Ma, J. H., Ma, W., Song, W., Chen, C., Tang, Y., Zhao, J., Huang, Y., Xu, Y. \& Zang, L. 2006 Fenton degradation of organic pollutants in the presence of low-molecular-weight organic acids: cooperative effect of quinone and visible light. Environmental Science \& Technology 40 (2), 618-624.

Ma, J. H., Ma, W., Chen, C., Ji, H. \& Zhao, J. 20II An efficient anthraquinone-resin hybrid co-catalyst for Fenton-like reactions: acceleration of the iron cycle using a quinone cycle under visible-light irradiation. Chemistry - An Asian Journal 6 (9), 2264-2268.

Nishiki, M., Tojima, T., Nishi, N. \& Sakairi, N. 2000 Betacyclodextrin-linked chitosan beads: preparation and application to removal of bisphenol. Carbohydrate Letters 4 (1), 61-67.

Ohko, Y., Ando, I., Niwa, C., Tatsuma, T., Yamamura, T., Nakashima, T., Kubota, Y. \& Fujishima, A. 200I Degradation of bisphenol A in water by $\mathrm{TiO}_{2}$ photocatalyst. Environmental Science \& Technology 35 (11), 2365-2368.

Onyonye, A. L., Mcintosh, A. \& Bolton, J. 1986 Mechanism of the photochemistry of $p$-benzoquinone in aqueous solutions. 1 . 
Spin trapping and flash photolysis electron paramagnetic resonance studies. The Journal of Physical Chemistry 90 (23), 6266-6270.

Richard, C., Vialation, D., Aguer, J. \& Andreux, F. 1997 Transformation of monuron photosensitized by soil extracted humic substances: energy or hydrogen transfer mechanism? Journal of Photochemistry and Photobiology A: Chemistry 111 (2), 265-271.

Staples, C. A., Dome, P., Klecka, G., Oblock, S. \& Harris, L. I998 A review of the environmental fate, effects, and exposures of bisphenol A. Chemosphere 36 (10), 2149-2173.

Suarez, S., Sueiro, R. \& Garrido, J. 2000 Genotoxicity of the coating lacquer on food cans, bisphenol A diglycidyl ether (BADGE), its hydrolysis products and a chlorohydrin of BADGE. Mutation Research-Genetic Toxicology and Environmental Mutagenesis 470 (2), 221-228.
Sun, Y. F. \& Pignatello, J. 1992 Chemical treatment of pesticide wastes. Evaluation of iron(III) chelates for catalytic hydrogen peroxide oxidation of 2,4-D at circumneutral $\mathrm{pH}$. Journal of Agricultural and Food Chemistry 40 (2), 322-327.

Zepp, R. G., Schlotzhauer, P. \& Sink, R. I985 Photosensitized transformations involving electronic energy transfer in natural waters: role of humic substances. Environmental Science \& Technology 19 (1), 74-81.

Zhan, M. J., Yang, X., Yang, H. \& Kong, L. 2005 Study on the effect of natural aquatic humic substances on the photodegradation of bisphenol A. Acta Scientiae Circumstantiae 25 (6), 816-820.

Zuo, Y. \& Hoigne, J. I992 Formation of hydrogen peroxide and depletion of oxalic acid in atmospheric water by photolysis of iron(III)-oxalato complexes. Environmental Science \& Technology 26 (5), 1014-1022.

First received 10 January 2014; accepted in revised form 23 May 2014. Available online 5 June 2014 